\title{
MigRACIÓN Y REMESAS: ¿̇ESTÁN AFECTANDO LA SUSTENTABILIDAD DE LA AGRICULTURA Y LA SOBERANÍA ALIMENTARIA EN CHIAPAS?
}

\author{
Migration and Remittances: Are They Affecting Agricultural Sustainability \\ and Food Sovereignty in Chiapas? \\ Helda Morales \\ Mariel Cristina Aguilar-Støen \\ Edwin Josué Castellanos-López
}

\begin{abstract}
Resumen:Coneste artículo se pretende contribuir al debate sobre el impacto de la migración internacionaly de las remesasen la agricultura. Presentamos los resultados de una encuesta realizada en 2011 sobre agricultura, combinados con muestreos de agrobiodiversidad en parcelas de familias con y sin migrantes de cuatro comunidades campesinas de Chiapas. En contra de lo esperado, los resultados sugieren que la migración no está provocando ni abandono de la agricultura, ni cambios sustanciales en el tipo de cultivos de las zonas estudiadas. Los datos apuntan a que la migración y las remesas podrían contribuir a prácticas agrícolas más sustentables y a la soberanía alimentaria.
\end{abstract}

Palabras clave: migración internacional, agroecología, soberanía alimentaria, agrobiodiversidad, remesas.

Abstract: Here, we contribute to the debate surrounding the impact of international migration and remittances on agriculture. In 2011, we surveyed families with and without migrants in four rural communities in Chiapas regarding their farming practices. We also sampled agrobiodiversity on the land managed by a subset of each group. Contrary to our expectations, the results suggest that out-migration has not spurred agricultural abandonment or substantial changes in the crops planted. Our data suggest that migration and remittances can contribute to sustainable farming practices and food sovereignty.

Keywords: international migration, agroecology, food sovereignty, agrobiodiversity, remittances.

Helda Morales, doctora por la Universidad de Michigan. Investigadora titular de El Colegio de la Frontera Sur, México. Temas de especialización: sistemas agroalimentarios sustentables y agroecología. Correo electrónico: hmorales@ecosur.mx.

Mariel Cristina Aguilar-Støen, doctora en manejo de recursos naturales por la Norwegian University of Life Sciences. Investigadora titular en el Centre for Development and Environment, Universidad de Oslo, Noruega. Temas de especialización: biodiversidad, ecología política, gobernanza ambiental. Correo electrónico: mariel.stoen@sum.uio.no.

Edwin Josué Castellanos López, doctor en ciencias ambientales por la Universidad de Indiana. Director del Centro de Estudios Ambientales y de e Biodiversidad, Universidad del Valle de Guatemala. Temas de especialización: cambio climático, proyectos de captura de carbono, monitoreo de la cobertura forestal con sensores remotos y manejo comunitario de recursos naturales. Correo electrónico: ecastell@uvg.edu.gt.
Enviado a dictamen: 14 de enero de 2014. Aprobación: 10 de octubre de 2014.

Revisiones: 1. 


\section{De las milpas ancestrales a la agroexportación}

- Provoca la migración el abandono de la agricultura? ¿Afectan las remesas a la sustentabilidad de la agricultura y a la seguridad alimentaria? Éstas son preguntas que a nivel internacional obtienen respuestas encontradas. Chiapas, uno de los estados más pobres de México, presenta condiciones interesantes para contribuir a este debate por la diversidad de formas de producción agrícola que se dan en su territorio (Morales, Ferguson y García-Barrios, 2008), así como por su reciente "explosión migratoria” (Martínez, 2013).

En Chiapas, la agricultura campesina se centra tanto en la producción de alimentos básicos - maíz y frijol一, como en la producción de cultivos para la exportación, como el café, y en la ganadería extensiva.

Aunque el cultivo de la milpa tradicional ha sido percibido por algunos autores como símbolo de pobreza (Sabines, 2007) y de deterioro ambiental (Nations, Primack y Bray, 1998), numerosos estudios muestran que la milpa bien manejada es un ejemplo de agricultura sustentable (Gliessman, 2002; Morales et al., 2008), la cual define Gliessman (2002) como aquella que emula a la naturaleza para aprovechar los servicios ecosistémicos de la biodiversidad, y que establece vínculos directos entre las familias productoras y las familias consumidoras. Así, la milpa tradicional chiapaneca -que intercala maíz, frijol, calabaza, árboles frutales y verduras - puede mejorar la vida en el suelo porque le brind a fertilidad, mantiene los insectos benéficos, que realizan la polinización y contribuyen al manejo biológico de plagas, y proporciona una dieta balanceada y culturalmente apropiada para las familias que la producen y para su comunidad (Morales, 2010; Morales et al., 2008).

Las políticas gubernamentales en Chiapas han favorecido la transformación de las milpas tradicionales en plantaciones de maíz, en monocultivo, y en cultivos para la agroexportación. Desde hace más de un siglo, los campesinos chiapanecos se han dedicado a la siembra de café y, más recientemente, han incursionado en la siembra de frutales y en la ganadería. Entre los sistemas destinados a la agroexportación, conviven monocultivos con alto uso de agroquímicos, ganadería extensiva y sistemas agroforestales orgánicos (Morales et al., 2008). Por otra parte, con más de setenta mil productores de café, miel, cacao, mango y leche orgánica, Chiapas se ha convertido en uno de los principales productores de productos agrícolas orgánicos de México (Gómez y Gómez, 2004).

El deterioro ambiental causado por los monocultivos y la ganadería intensiva se encuentra bien documentado (García-Barrios et al., 2009, Morales et al., 2008) y cada vez es más amplio el consenso sobre el hecho de que estos sistemas productivos no contribuyen a la seguridad alimentaria (Unctad, 2013). En cuanto a los sistemas agroforestales de café orgánico, también está bien documentado el papel positivo que desempeñan dichos sistemas en la conservación de la biodiversidad y su sustentabilidad ambiental (Perfecto y Vandermeer, 2010), pero surgen dudas sobre la sostenibilidad de los vínculos entre las personas productoras con las personas consumidoras, y sobre el aporte de los sistemas cafetaleros a la alimentación local (Méndez et al., 2010).

\section{La agricultura y la migración en Chiapas}

En Chiapas, la migración a Estados Unidos se intensificó en 2001, principalmente como consecuencia de la falta de tierras, las políticas agrarias de corte neoliberal, la caída de los precios del café y eventos climáticos extremos, como los huracanes Mitch y Stan (Eakin et al., 2013; Santacruz, Pérez y Palacio, 2007; Villafuerte y García, 2008). En una década, pasó de ser uno de los estados con menores tasas de migración a uno de los principales expulsores de campesinos (López, 2009; Martínez, 2013). Siendo Chiapas tan dependiente de la agricultura y de la mano de obra agrícola, este boom migratorio podría tener un gran impacto en las zonas rurales y sus pobladores.

Nos propusimos, por lo tanto, explorar diferencias entrefamilias con y sin migrantes en cuatro comunidades rurales de Chiapas, en relación con la agricultura que practican y su seguridad alimentaria, y desde una perspectiva de sustentabilidad agroecológica. 
Helda Morales, Mariel Cristina Aguilar-Støen, EdWin Josué Castellanos-López

\section{Metodología}

\section{Comunidades estudiadas}

Elestudio se realizó en cuatro comunidades chiapanecas: 1) La Competencia, en el municipio de Huitiupán, en la región Norte, 2) El Águila, en el municipio de Cacahoatán, en la región de Soconusco, 3) Veinticuatro de Febrero, en el municipio de Villa Corzo, en la región Frailesca, y 4) Manuel Ávila Camacho, en el municipio de Tonalá, en la región Costa (ver mapa l).

Se buscó que las comunidades elegidas estuvieran localizadas en distintas regiones geográficas del estado y que presentaran un porcentaje significativo de familias con migrantes en Estados Unidos (ver cuadro 1). Por otra parte, ha de destacarse que el estudio de la migración genera desconfianza entre los pobladores porque temen perder los subsidios del gobierno si éste se entera de los ingresos que reciben por las remesas, o ser vulnerables a la extorsión por parte de delincuentes. Por este motivo, en tres de los casos fuimos presentados a las autoridades ejidales por colegas que realizaban otras investigaciones en la zona. A continuación se describirá brevemente cada una de estas comunidades.

La Competencia: esta comunidad del municipio de Huitiupán está situada a 420 metros sobre el nivel del mar y goza de un clima cálido húmedo con lluvias en verano. La migración inició en La Competencia después de la caída de los precios del café en 2001. De las 102 familias encuestadas en esta comunidad, el $48 \%$ tiene o ha tenido migrantes en Estados Unidos, y el 34\% recibe remesas. Muchos han migrado a Oklahoma para trabajar en una cantera. La mayoría de las familias (83\%) son propietarias de tierra agrícola. El tamaño de las parcelas varía de 75 a 18500 metros cuadrados. El 47,6\% de las familias encuestadas tiene entre 2500 y 10000 metros cuadrados, mientras que el $37 \%$ cuenta con parcelas de menos de 2500 metros cuadrados. Casi la totalidad de las familias encuestadas siembra maíz, y el 75\% de ellas siembra, además, otros cultivos, como café y frijol. El 90\% de las familias produce para el autoconsumo o para vender en la misma comunidad y sus alrededores. De las familias encuestadas, el 18\% tiene ganado.
MIGRACIÓN Y REMESAS: ¿ESTÁN AFECTANDO LA SUSTENTABILIDAD DE LA AGRICULTURA Y LA SOBERANÍA ALIMENTARIA EN CHIAPAS?
El Águila: esta comunidad del municipio de Cacahoatán está situada a 1255 metros sobre el nivel del mar y goza de un clima templado húmedo. La migración inició en El Águila como consecuencia del huracán Stan en 2005. De las 102 familias encuestadas en esta comunidad, el 54\% tiene migrantes en Estados Unidos, y el $42 \%$ de ellas recibe remesas. La mayoría de quienes migran lo hace anualmente mediante un programa para trabajar en invernaderos de tomate en Florida. Un alto porcentaje de familias (75\%) son propietarias de tierra agrícola. El tamaño de las parcelas varía entre 21 y 8000 metros cuadrados. El 12\% de las familias encuestadas tiene más de 2500 metros cuadrados, mientras que el 88\% cuenta con parcelas menores de 2500 metros cuadrados. Ninguna de las familias encuestadas tiene ganado, mientras que todas siembran café para exportación, y sólo el 3\% cultiva también maíz para su autoconsumo.

Veinticuatro de Febrero: esta comunidad, del municipio de Villa Corzo, se encuentra a 640 metros sobre el nivel del mar y goza de un clima cálido subhúmedo. La migración inició en 1990. De las 38 familias encuestadas, el 48\% tiene migrantes en Estados Unidos, quienes se dedican fundamentalmente a trabajos agrícolas, como la siembra de tabaco o el corte de pasto, pero sólo el 28\% recibe remesas. La mayoría (79\%) de las familias son propietarias de tierra agrícola. La extensión de las parcelas oscila entre 700 y 92000 metros cuadrados. El 37\% de las familias encuestadas tiene más de 10000 metros cuadrados, y el 33\% parcelas menores de 2500 metros cuadrados. El 60\% de las familias afirmó tener ganado. La mayoría (76\%) cultiva maíz y frijol; y el 24\%, sólo maíz. El 56\% de las familias encuestadas destina su producción al autoconsumo o a la venta en la misma comunidad, a la vez que está tratando de recuperar la milpa tradicional para rescatar las semillas locales y evitar el uso de agroquímicos.

Manuel Ávila Camacho: esta comunidad, llamada también Ponte Duro, del municipio de Tonalá, está ubicada a dos metros sobre el nivel del mar y cuenta con clima cálido subhúmedo. La migración inició en 1990 por la imposibilidad de expandir las tierras agrícolas. De las 102 familias encuestadas en esta comunidad, el 36\% tiene migrantes en Estados Unidos, y el 34\% recibe remesas. 
La mayoría (87\%) de las familias no son propietarias de tierra agrícola. El tamaño de sus parcelas varía entre 14 y 12000 metros cuadrados. El 92\% de las familias encuestadas tiene menos de 2500 metros cuadrados. El 62\% de las familias encuestadas tiene ganado y son pocas las familias que se dedican a la agricultura. De ellas, el 57\% siembra maíz en monocultivo; y el resto, maíz asociado con otros cultivos. El 29\% de ellas dedica la cosecha al autoconsumo, y el 58\% la vende en la comunidad o en comunidades vecinas. Muchas se dedican a la pesca, y un grupo de retornados tiene un programa ecoturístico para la protección del mangle.

\section{Encuesta}

En la primera mitad de 2011 se realizó una encuesta en las comunidades estudiadas. En tres comunidades se encuestó a 102 familias; en Veinticuatro de Febrero, quees una comunidad pequeña, sólo se entrevistó a 38. En total fueron entrevistadas 344 familias seleccionadas al azar. Para ello, se trazó un croquis de cada comunidad que se dividió en barrios, y en cada barrio se seleccionaron las casas donde se realizarían las entrevistas de una forma estratificada, dependiendo de la densidad de población del barrio. La entrevista se realizó a los jefes o jefas de familia, a quienes se les preguntó sobre diversos temas, como tenencia de la tierra, migración a Estados Unidos y remesas, manejo agrícola y acceso a alimentos (ver anexo 1). Posteriormente se analizaron los porcentajes de estas variables considerando si se trataba de familias sin migrantes, de familias con migrantes que recibían remesas o de familias con migrantes que no recibían remesas.

\section{Estudio de diversidad de plantas útiles en milpas}

En cada comunidad, de la lista de personas encuestadas se seleccionaron al azar seis familias con migrantes y seis familias sin migrantes. A cada una de estas familias se le pidió permiso para visitar su área de cultivo, en la que se calculó la diversidad de cultivos, herbáceas, arbustos y árboles asociados. Para ello, se demarcaron cuatro transectos de diez metros de largo y uno de ancho, localizados al azar dentro del área de cultivo de cada familia, y se identificaron y contaron todas las plantas dentro del transecto. Con la ayuda de la familia, se anotó el nombre común de cada planta y sus usos en el caso de que los tuvieran. En cada parcela se calculó el índice de diversidad de Shannon y el índice de Simpson con el programa EstimateS.

\section{Resultados}

\section{Sobre la tenencia de la tierra}

El 59\% de las familias dijo que poseía tierra agrícola en el momento de la encuesta. Entre las familias con migrantes que recibían remesas, el 62\% tenía propiedades agrícolas. El porcentaje fue un poco más alto entre las familias que dijeron no recibir remesas (69\%), y un poco menor entre las familias sin migrantes (56\%). De las familias con migrantes, más del 58\% dijo que no tenía terrenos antes de migrar.

\section{¿Cómo es la agricultura que practican los encuestados? ¿Quécultivan?}

De todas las familias encuestadas, el 39\% se dedicaba solamente a la producción de café, el $25 \%$ a la producción de maíz y frijol, el 16\% a la producción sólo de maíz y el 14\% a la producción de milpa diversificada. No se observaron diferencias importantes entre las familias con y sin migrantes. El porcentaje de familias que se dedicaba exclusivamente a la siembra de café era similar entre las familias sin migrantes (35\%) y las familias con migrantes que no recibían remesas (29\%). Entre las familias con migrantes que sí recibían remesas, el porcentaje era un poco más alto $(48 \%)$, pero no se encontró evidencia de que esa tendencia se debiera a la migración. Los porcentajes de las familias que se dedicaban exclusivamente a la siembra de maíz fueron similares entre las familias sin miembros migrantes $(18 \%)$, las que los tenían pero no recibían remesas (13\%), y las que los tenían y recibían remesas (15\%). Lo mismo ocurrió entre las familias que se dedicaban a la producción diversificada. En este sentido, cultivaban 
maíz, frijol y otros productos el 14\% de las familias que no contaba con miembros migrantes, el 13\% de las que tenían migrantes pero no recibía remesas, y el 16\% de las familias con migrantes que recibía remesas.

\section{Laganadería}

De las familias encuestadas, el 20\% se dedicaba a la ganadería, además de a la agricultura. Tenían ganado el $38 \%$ de las familias con migrantes sin remesas, el 20\% de las familias con migrantes que recibía remesas y el 17\% de las familias sin migrantes. Sin embargo, al examinar el número de cabezas de ganado, se observó que la mayoría de las familias sin migrantes (53\%) y el total de las familias con migrantes que no recibía remesas (100\%) tenían entre una y cinco cabezas, mientras que las familias con migrantes que recibían remesas tenían entre seis y diez cabezas (50\%). El número de familias con ganado aumentó ligeramente después de que inició la migración (6\%), pero apenas el 3\% de las familias dijo que había comprado ganado con el dinero de las remesas.

\section{¿Quiénes trabajan la tierra?}

De las familias encuestadas, el 63\% afirmó que la agricultura era la ocupación principal del jefe de familia — sólo el 2,2\% se trataba de jefas de familia-. En el 81\% de las familias se empleaba únicamente mano de obra familiar y, de este porcentaje, en el $47 \%$ la mano de obra era la proporcionada por el jefe de la familia. Este porcentaje fue más elevado en el caso de las familias sin migrantes (59\%), y menor entre las que tenían miembros migrantes y recibían remesas (30\%). Solamente el 3.7\% de las familias encuestadas dependía completamente de trabajadores contratados para trabajar su tierra, porcentaje que aumentó ligeramente en los casos de aquellas que tenían migrantes y recibían remesas (4.3\%).

\section{¿Cómo se manejan las parcelas agrícolas?}

Agrobiodiversidad: El 45\% de las familias entrevistadas que sembraba maíz, lo hacía en monocultivo, el 13\% intercalaba maíz y frijol, y el 42\% sembraba más de tres cultivos intercalados, que incluían calabaza, cilantro, arveja, chile, chayotes, pepino, tomate o coliflor, y hierbas como mostaza, hierbamora, bledo, chipilín y verdolaga.

Según la encuesta, no parece haber diferencias entre las familias con y sin migrantes en relación con el cultivo diversificado de las milpas, dado que sembraban maíz en policultivo el $40 \%$ de las familias sin migrantes, el $34 \%$ de las familias con migrantes que no recibía remesas, y un $49 \%$ de las familias con migrantes que recibía remesas. Es interesante notar que, entre las familias con migrantes, las que recibían remesas parecían tener con más frecuencia milpas diversificadas, a diferencia de las familias que no las recibían.

Los datos tomados en las parcelas de algunos de los encuestados, relacionados con la diversidad de plantas útiles, sugerían también que no había diferencia significativa entre familias con y sin migrantes (ver figura 1), aunque parece que había una tendencia consistente en la mayoría de las comunidades estudiadas a que las familias con migrantes que no recibían remesas cultivaran menor diversidad de plantas en sus parcelas.

Barbecho: El 37\% de las familias encuestadas no dejaba descansar la tierra antes de volver a sembrar maíz, mientras que el resto lo hacía entre cinco meses y más de un año. Se observó una ligera diferencia entre las familias que recibían remesas y el tiempo que dejaban descansar la tierra: el 39\% de las familias sin migrantes y el 35\% de las familias con migrantes que no recibían remesas no dejaban descansar la tierra, mientras que el $27 \%$ de las familias con migrantes que recibían remesas dejaban descansar la tierra durante más de un año.

Plaguicidas: En cuanto al uso de agroquímicos en general - herbicidas, insecticidas o fertilizantes-, la mayoría de las familias encuestadas dijo que los utilizaba, y su uso no parecía estar relacionado con la migración. Sin embargo, en el caso de los insecticidas, en Manuel Ávila Camacho y en La Competencia sí utilizaban insecticidas más familias con migrantes que recibían remesas, que aquellas que no tenían migrantes o no recibían remesas. En el caso de los herbicidas, un alto porcentaje de las familias encuestadas los utilizaba para 
el manejo de malezas, con excepción de las residentes en El Águila, donde principalmente se produce café orgánico. En contra de lo esperado, se observó que, en general, usaban herbicidas más familias sin migrantes que aquellas que sí los tenían (ver figura 2). Ninguna familia manifestó haber adoptado prácticas agrícolas aprendidas en Estados Unidos en sus parcelas ni haber traído semillas.

\section{Inversión de remesas en la agricultura}

La mayoría de las familias con migrantes que recibían remesas utilizaban estas últimas para afrontar los gastos del hogar, mientras que la agricultura era el rubro en el que menos invertían el dinero procedente de las remesas (5.7\%). Las familias con migrantes que recibieron remesas e invirtieron en la agricultura destinaron estos recursos para contratar jornaleros agrícolas $(22 \%)$, para la siembra (11,5\%) y para comprar agroquímicos (8\%) $\mathrm{u}$ otros productos agropecuarios - como alambres o madera- (2\%). El 14\% dijo haber adquirido tierras agrícolas con dinero procedente de remesas.

\section{Soberanía y seguridad alimentaria}

La mayoría de las familias encuestadas (54\%) producía para el mercado, el 23\% vendía parte de su producción a nivel local y el resto lo destinaba al autoconsumo, mientras que el $15 \%$ producía sólo para el autoconsumo.

Casi nadie afirmó haber pasado hambre $(2,6 \%)$ o haber dejado de comer los alimentos que acostumbraba en el año anterior a la encuesta (7,6\%). El 97\% de los migrantes que recibía remesas utilizaba por lo menos parte de ellas para comprar alimentos.

\section{Discusión}

\section{¿La migración repercute en la sustentabilidad de la agricultura en Chiapas?}

Estudios realizados años atrás en México sugerían que la migración tenía un impacto negativo sobre la agricultura (García-Barrios y García-Barrios, 1990). Este fenómeno se explicaba, en algunos casos, por la pérdida de mano de obra agrícola (Massey, Goldring y Durand, 1994), por la falta de inversión de las remesas en la agricultura (Mines y De Janvry, 1982) o por la inversión de las remesas en la ganadería extensiva (García et al., 2009; Schmook y Radel, 2009). En cambio, en las comunidades estudiadas se comprobó que la migración no provocaba abandono de la agricultura campesina ni cambios sustanciales en ella. Un proceso similar ha sido reportado en el altiplano de Ecuador, donde, en contra de las predicciones, la agricultura de subsistencia se ha mantenido a pesar de las altas tasas de migración a Estados Unidos y de la poca inversión de remesas en el campo (Jokisch, 2002). Según Taylor (2001), la migración tiene menos impactos negativos cuando la pérdida de mano de obra no es significativa, cuando las remesas llegan a los hogares más pobres y cuando éstas son invertidas en los procesos productivos. En los estudios de caso que se realizaron en el marco de este trabajo, únicamente se observó el primero de los postulados de Taylor, dado que, aunque un porcentaje considerable de familias tenía migrantes en Estados Unidos (entre $36 \%$ y $54 \%$ ), en las comunidades estudiadas no se percibió falta de mano de obra agrícola. Será interesante dar seguimiento y determinar si la tendencia aquí observada se mantiene en comunidades con tasas de migración más elevadas. También será interesante para estudios futuros determinar si existen diferencias entre comunidades con tierras ejidales, como las aquí estudiadas, y comunidades sin tierras ejidales. En este sentido, a pesar de que se modificó el artículo 27 de la Constitución mexicana en 1994 para permitir la venta de terrenos ejidales, la mayoría de los campesinos no ha vendido sus tierras y aún sienten que pertenecer al ejido y ser campesinos son derechos adquiridos a través de sus padres y abuelos, lo que para ellos es motivo de orgullo.

Más de la mitad de las familias encuestadas ha abandonado la siembra de cultivos para autoconsumo y ha incursionado en la agricultura para el mercado regional o de exportación, pero no existe evidencia de que el cambio esté relacionado con la migración. En Chiapas, en general, y sobre todo en la última década, las políticas agrarias han estimulado a las familias 
campesinas a abandonar los cultivos destinados a la alimentación de la comunidad, para sustituirlos por cultivos para los mercados regional e internacional, como árboles frutales - aguacates, mangos o peras-, café, ganadería y agrocombustibles (Sabines, 2007). En el caso de la región de Soconusco, la agricultura de exportación ha sido la norma desde hace más de un siglo (Santacruz, Pérez y Palacio, 2007). Es importante destacar aquí que este tipo de agricultura, impulsado por los gobiernos como estrategia de desarrollo, no ha disminuido la necesidad de migrar a Estados Unidos en busca de mejores oportunidades.

En términos de manejo agrícola y sustentabilidad, en las comunidades chiapanecas estudiadas tampoco se notaron tendencias claras relacionadas con la migración internacional. Sin embargo, las familias con migrantes llevaban a cabo algunas prácticas más sustentables que las familias sin migrantes, como dejar descansar más tiempo el suelo agrícola o usar menos herbicidas, lo que a largo plazo podría derivar en impactos favorables sobre la sustentabilidad de la agricultura, la conservación de los recursos naturales y la salud de las personas (Gliessman, 2002). Por ello, será importante indagar en un futuro cercano sobre estas tendencias que parecen contraintuitivas, puesto que en general se da por hecho que las prácticas agroecológicas requieren de más mano de obra (Perfecto y Vandermeer, 2010), y que el recibir remesas permite adquirir y utilizar más agroquímicos. Ninguno de los encuestados dijo haber aplicado nuevas técnicas agrícolas aprendidas en Estados Unidos, por ellos o por sus familiares que migraron; sin embargo, varios manifestaron haber ganado conciencia ambiental. Puesto que no conocemos estudios anteriores que hayan relacionado la diversidad de la parcela con la migración, esperamos que éste sea usado como indicador de sustentabilidad agrícola y alimentaria en estudios futuros de migración.

\section{¿Está afectando la migración a la soberanía y seguridad alimentarias?}

Aunque casi ningún entrevistado dijo pasar hambre ni que se vio en la necesidad de hacer cambios en los alimentos que acostumbraba consumir, algunas familias podrían ser vulnerables a perder su soberanía alimentaria, aunque esto no parece estar relacionado con la migración. Se menciona lo anterior porque depender del mercado para la adquisición de alimentos no sólo deja a las familias en una situación de vulnerabilidad alimentaria, sino que las hace propensas a adquirir alimentos con poco valor nutritivo. En este sentido, la población de Chiapas, como la de otros estados mexicanos, está padeciendo problemas de salud por el aumento en el consumo de alimentos industrializados y, como consecuencia, en las comunidades campesinas se presentan elevados índices de desnutrición y obesidad (Velasco-Martínez et al., 2009). En la comunidad El Águila, como en muchas otras comunidades chiapanecas, desde hace años las familias abandonaron la producción de sus propios alimentos para dedicarse principalmente a la producción de cultivos para la exportación. En este sentido, ellos mismos reconocieron que, dada la inestabilidad de los precios del café y los recientes eventos climáticos extremos que les habían afectado, dedicarse exclusivamente a la producción de café los hacía vulnerables en cuanto a su alimentación. En la comunidad Manuel Ávila Camacho, el programa de protección del manglar que desarrollaban junto con la Comisión Nacional de Áreas Protegidas (CONANP) les impedía sembrar sus alimentos y, aunque afortunadamente muchos de ellos se dedicaban a la pesca y obtenían del mar parte de su comida, en casos de enfermedad o de eventos climáticos extremos, el no tener maíz y frijol almacenado también les hacía vulnerables. En La Competencia y en Veinticuatro de Febrero, la migración pareció haber favorecido la soberanía alimentaria. Por ejemplo, el comisariado ejidal de La Competencia refería que el envío de remesas permitió la activación de la producción de alimentos en la comunidad, de modo que las familias que se quedaron podían vender sus productos, como maíz y frijol, allí mismo, lo que contribuyó a mejorar la economía y la dieta de todos. En Veinticuatro de Febrero, algunos retornados iniciaron un programa para la recuperación de las variedades locales de frijol y maíz, así como para la producción de milpa orgánica. En este sentido, un 
informante clave dijo que el hecho de estar en Estados Unidos le permitió revalorar sus cultivos y su cultura gastronómica.

\section{Conclusiones}

En las comunidades estudiadas de Chiapas, la migración no parece estar provocando un abandono de la agricultura. Por el contrario, aunque en pequeñas proporciones, las familias que reciben remesas están invirtiendo en la compra de tierras y de ganado, y en la contratación de jornaleros para el trabajo agrícola. Asimismo, la migración tampoco parece estar asociada con una menor inversión en cultivos de subsistencia ni con una disminución significativa de la agrobiodiversidad, sino que más bien la migración y las remesas asociadas podrían estar subsidiando la soberanía alimentaria de las comunidades estudiadas cuando las remesas se invierten en la producción de alimentos con base en un sistema diversificado.

En cuanto a las prácticas de cultivo, se observaron dos posibles efectos positivos de la migración sobre la sustentabilidad agrícola: en primer lugar, las familias con migrantes parecen dejar descansar la tierra durante más tiempo, lo que posiblemente ayuda a conservar la fertilidad del suelo y, en segundo lugar, aunque la mayoría de las familias usa herbicidas, la tendencia es a usarlos menos entre las familias con migrantes, lo que reduce así la contaminación por estos productos tóxicos.

\section{Notas}

${ }^{1}$ Esta investigación fue financiada por el proyecto MIRLU de la Universidad de Oslo.

\section{Referencias bibliográficas}

Eakin, Hallie et al. (2013), "Coffee, Disasters and SocialEcological Resilience in Guatemala and Chiapas, Mexico". En Boulter, S. et al. (eds.), Natural Disasters and Adaptation to Climate Change. Nueva York, Cambridge University Press, pp. 174-180.
García-Barrios, Raúl y Luis García-Barrios (1990), "Environmental and Technological Degradation in Peasant Agriculture: a Consequence of Development in Mexico". En World Development, 18(11), pp. 1569-1585.

García-Barrios, Luis et al. (2009), "Neotropical Forest Conservation, Agricultural Intensification, and Rural Out-migration: the Mexican Experience". En Bioscience, 59(10), pp. 863-873.

Gliessman, Stephen R. (2002), Agroecología: procesos ecológicos en agricultura sostenible. Turrialba, Costa Rica, CATIE

Gómez Tovar, L. y M.A. Gómez Cruz (2004), "La agricultura orgánica en México y en el mundo". En Biodiversitas, núm. 55, pp. 13-15.

Jokisch, B.D. (2002), "Migration and Agricultural Change: the Case of Small Holder Agriculture in Highland Ecuador". En Human Ecology, 30(4), pp. 523-550.

López Arévalo, J. (2009), Globalización, migración yeconomía chiapaneca. Chiapas, Universidad Autónoma de Chiapas.

Massey, D.S., L. Goldringy J. Durand(1994), “Continuities in Transnational Migrations: an Analysis of Nineteen Mexican Communities". En American Journal of Sociology, 99(6), pp. 1492-1533.

Martínez Velasco, G. (2013), "Migración internacional chiapaneca: trayectorias de movilidad, sociodemográficas, y condiciones sociales". En Revista Pueblos y Fronteras, 8(15), pp. 50-91.

Méndez, E. et al. (2010), "Effects of Fair Trade and Organic Certifications on Small-Scale Coffee Farmer Households in Central America and Mexico". En Renewable Agriculture and Food Systems, 25(3), pp. 236-25l. Mines, R. y A. de Janvry (1982), "Migration to the United States and Mexican Rural Development: a Case Study". En The Geographical Journal, 163(2), pp. 198-206.

Morales, H., B. Ferguson y L. García-Barrios (2008), "Agricultura: la cenicienta de la conservación en Mesoamérica”. En Harvey C.yJ. Sáenz (eds.), Evaluación y conservación de la biodiversidad en paisajes fragmentados de Mesoamérica. Costa Rica, INBio, pp. 47-73.

Morales, H. (2010), "Enfrentando la crisis alimentaria y ambiental". En La Jornada del Campo, núm. 34, 17 de julio de 2010. 
Nations, J., R.B. Primack y D. Bray (1998), "Introduction: the Maya Forest". En Primack, R.B. et al. (eds.), Timber, Tourists, and Temples: Conservation and Development in the Maya Forest of Belize, Guatemala, and Mexico. Washington, Island Press, pp. XIII-XX.

Perfecto, I. y J. Vandermeer (2010), "The Agroecological Matrix as Alternative to the Land Sparing / Agriculture Intensification Model". En Proceedings of the National Academy of Sciences, 107(13), pp. 5788-5791.

Sabines, J. (2007), Primer informe de gobierno, Tuxtla Gutiérrez, Chiapas, Gobierno del Estado.

Santacruz de León, E., E. Pérez Villalba y V. Palacio Muñoz (2007), "Agricultura de exportación, migración y remesas: el caso del Soconusco, Chiapas, México". En Observatorio de la Economía Latinoamericana, núm. 75. Disponible en www.eumed.net/cursecon/ecolat/ mx/2007/spp.htm [consultado 2 de diciembre de 2013].

Schmook, B. y C. Radel (2009), "Migración internacional desde un área de frontera agrícola y reserva ecológica: el caso del sur de la península de Yucatán". En Serrano, J.y R.G. Martínez-Velasco (coords.), Una aproximación a las migraciones internacionales en la frontera sur de México. San Cristóbal de Las Casas, Chiapas, El Colegio de la Frontera Sur/Red de Estudios Migratorios en la Frontera Sur de México, pp. 71-98.

Taylor,J.Edward(2001), “Migración: nuevas dimensiones y características, causas, consecuencias e implicancias para la pobreza rural". En Stamoulis, Kostas G. (ed.), Agricultura, alimentación y desarrollo agrícola. Temas actuales y emergentes para el análisis económico y la investigación de políticas. S.l., FAO. Disponible en http:// www.fao.org/docrep/003/x9808s/x9808s07.htm [consultado el 2 de diciembre de 2013].

UNCTAD. United Nations Conference on Trade and Development (2013). Trade and Environment Review. S.l., Naciones Unidas.

Velasco-Martínez, R.M. et al. (2009), "Obesidad y resistencia a la insulina en adolescentes de Chiapas". En Nutrición Hospitalaria, vol. 24(2), pp. 187-192.
Villafuerte Solís, Daniel y María del Carmen García Aguilar (2008), "Algunas causas de la migración en Chiapas". En Liminar. Estudios Sociales y Humanísticos, 14(21), pp. 4l-58.

\section{Anexo 1. Preguntas realizadas durante la encuesta:}

¿Tiene ahora familiares (que son o eran parte de su hogar) en el extranjero?

¿Tiene o tuvo parientes en el extranjero que le envían o enviaron dinero? ¿O estuvo usted en el extranjero y le enviaba dinero a su familia?

¿Tiene propiedad agrícola o forestal?

¿Es usted dueño de su parcela?

Si recibe remesas, zalguna de estas parcelas las adquirió gracias a las remesas recibidas? ¿Usó el dinero de las remesas para comprar estas parcelas o completar el dinero para pagarlas?

¿Cómo utiliza la tierra en su parcela?

¿Tiene ganado (cuántas cabezas)?

¿Qué cultivos siembra?

Para el cultivo de maíz, ipor cuánto tiempo deja descansar la tierra antes de volver a sembrar maíz?

¿Siembra algún producto intercalado con el maíz? (¿Cuál?)

¿Tuvo su familia problemas para obtener comida el año pasado?

¿Su familia pasó algunos días sin comer debido a la falta de alimentos?

¿Su familia compró alimentos más baratos en lugar de lo que acostumbran comer?

¿Tenía usted terreno o parcela antes de que su familiar o usted migraran?

¿Qué producía en su terreno antes de recibir remesas/ antes de migrar?

¿Tenía usted ganado antes de que usted o su familiar migraran?

¿Cuántas cabezas de ganado tenía su familia antes de recibir remesas? 
Figura 1. Diversidad de plantas útiles en las parcelas agrícolas de familias con y sin migrantes

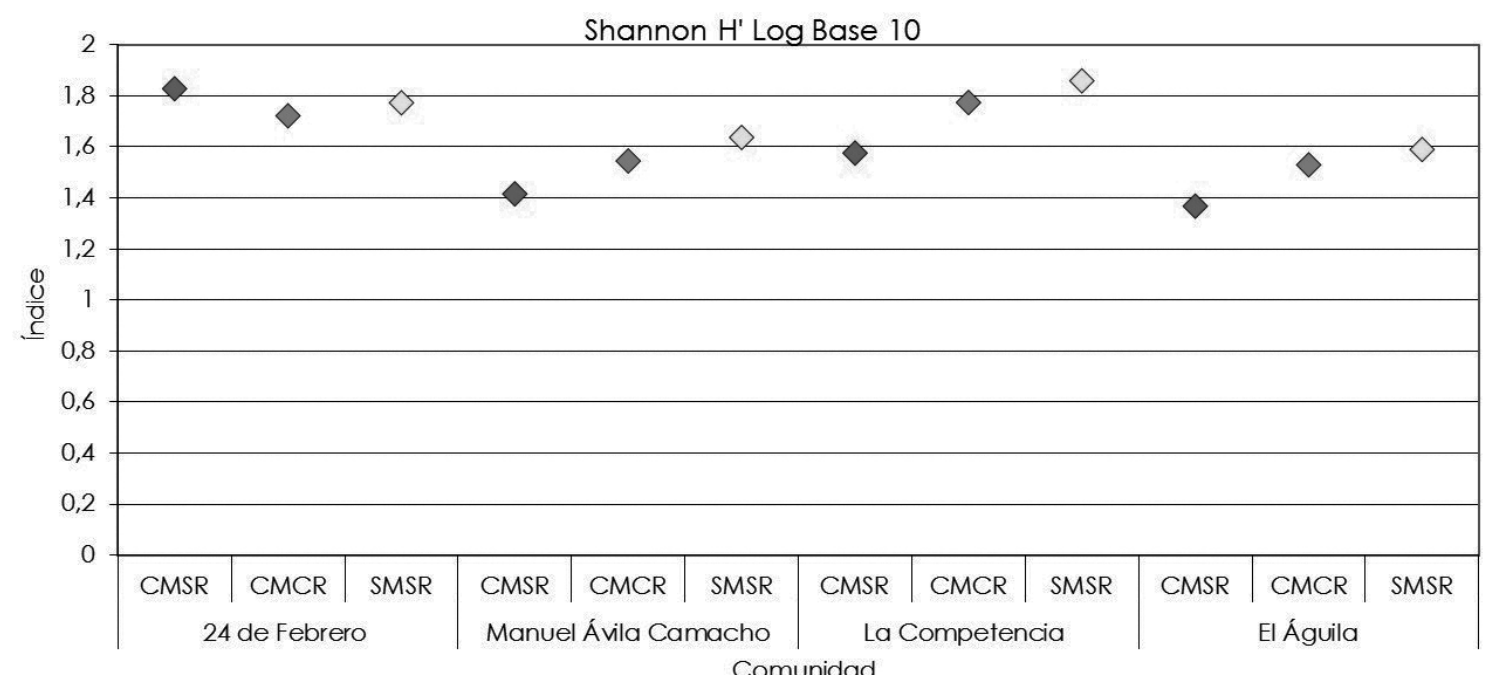

Comunidad

Los datos representan el índice de Shannon. CMSR: familia con migrante sin remesa. CMCR: familia con migrante con remesa. SMSR: familia sin migrante. $\mathrm{N}=48$. Fuente: elaboración propia.

Figura 2. Porcentaje de familias que usa herbicidas

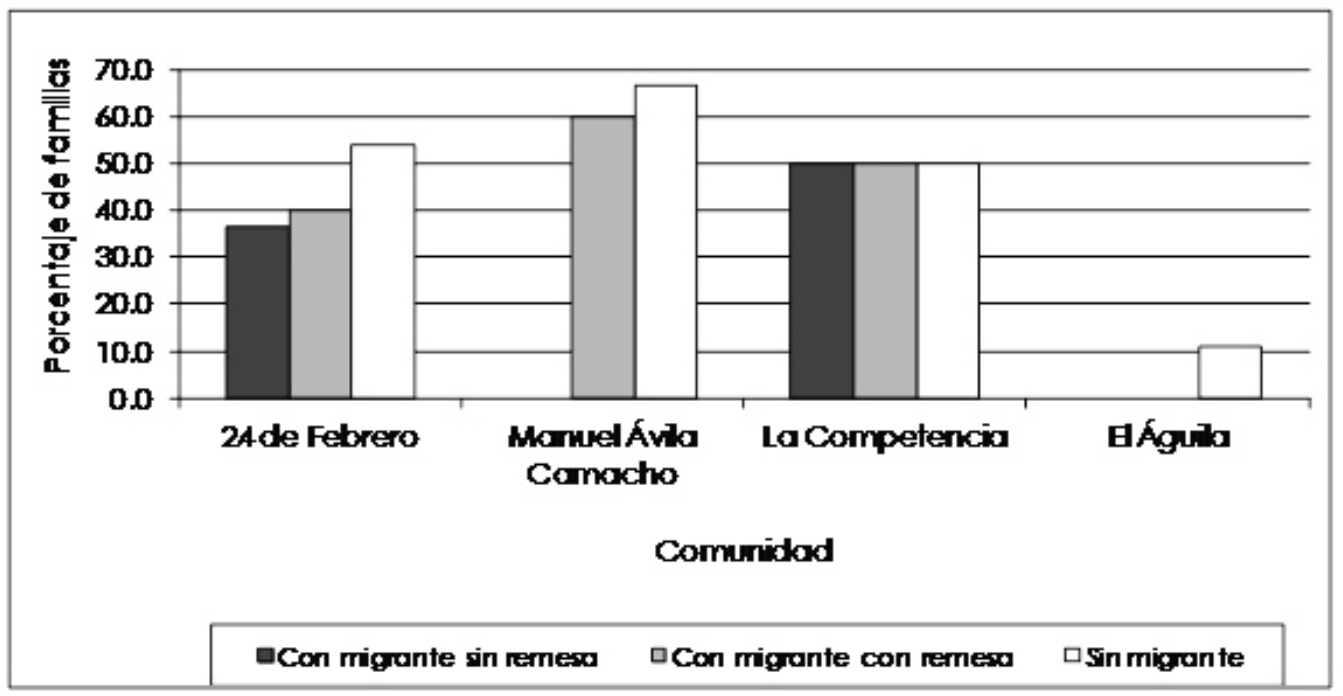

Fuente: elaboración propia. 
Mapa 1. Ubicación de las comunidades estudiadas:

El Águila, Ávila Camacho, Veinticuatro de Febrero y La Competencia

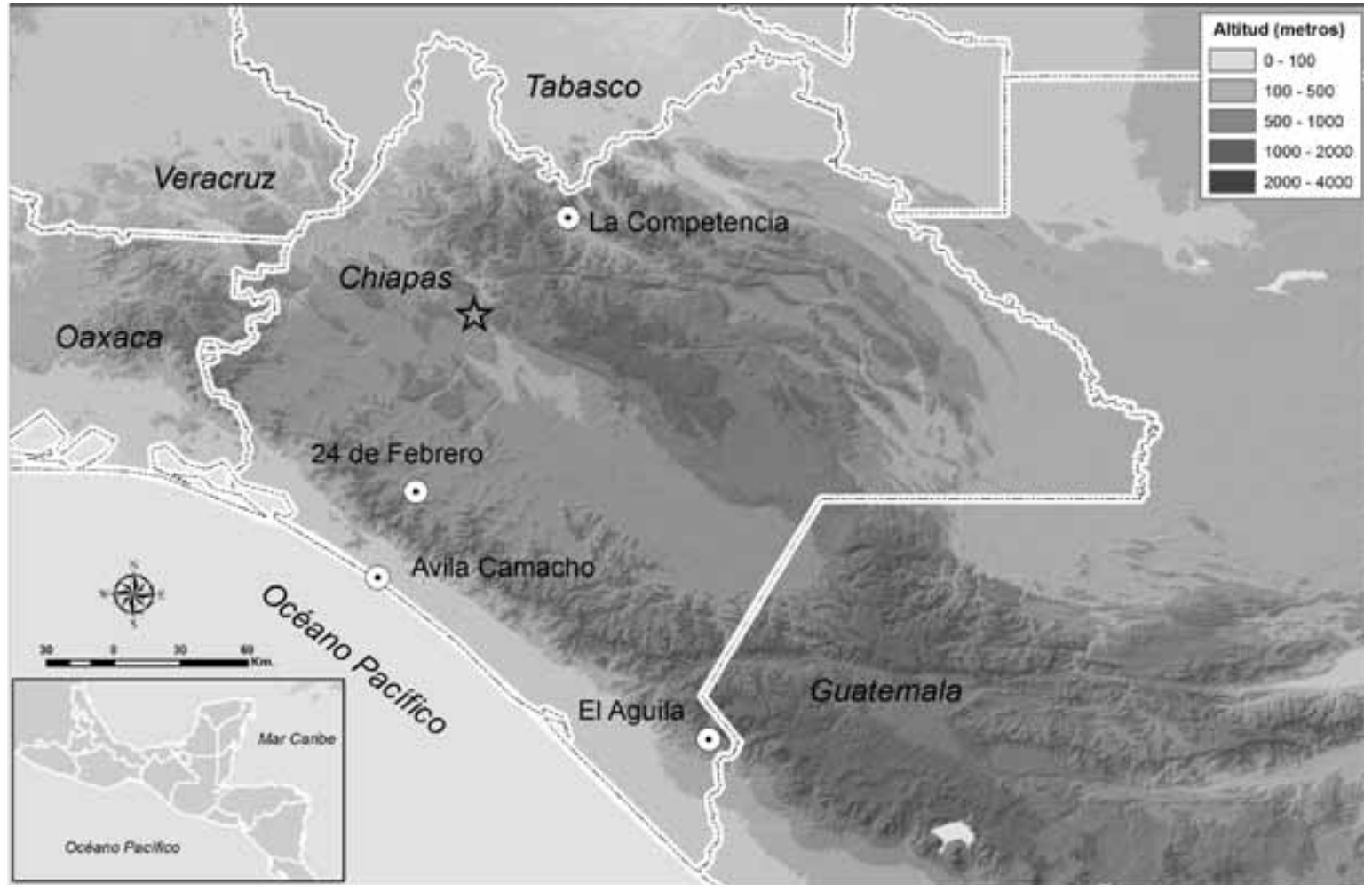

Fuente: Óscar Rolando González Rivera, del Centro de Estudios Ambientales de la Universidad del Valle de Guatemala. 
Cuadro 1. Características de las comunidades estudiadas

\begin{tabular}{|c|c|c|c|c|}
\hline & $\begin{array}{l}\text { El Águila, } \\
\text { Cacahoatán }\end{array}$ & $\begin{array}{l}\text { La Competencia, } \\
\text { Huitiupán }\end{array}$ & $\begin{array}{c}\text { Manuel Ávila } \\
\text { Camacho, Tonalá }\end{array}$ & $\begin{array}{c}\text { Veinticuatro de } \\
\text { Febrero, Villa } \\
\text { Corzo } \\
\end{array}$ \\
\hline $\begin{array}{c}\text { Cobertura } \\
\text { forestal }\end{array}$ & Bosque mesófilo & $\begin{array}{l}\text { Bosque tropical } \\
\text { Iluvioso }\end{array}$ & Mangle & $\begin{array}{c}\text { Bosque seco } \\
\text { tropical }\end{array}$ \\
\hline $\begin{array}{l}\text { Deforestación } \\
\text { e historia del } \\
\text { asentamiento }\end{array}$ & $\begin{array}{c}\text { Establecida en } \\
\text { 1934. Cafetales bajo } \\
\text { sombra de bosque } \\
\text { original }\end{array}$ & $\begin{array}{l}\text { Establecida en } 1938 . \\
\text { Bosque remplazado } \\
\text { casi en su totalidad } \\
\text { por pastizales }\end{array}$ & $\begin{array}{c}\text { Establecida en } \\
\text { 1934. Mangle } \\
\text { remanente bajo } \\
\text { reserva }\end{array}$ & $\begin{array}{c}\text { Establecida en } 1999 . \\
\text { Bosque remplazado } \\
\text { casi en su totalidad } \\
\text { por cultivos }\end{array}$ \\
\hline $\begin{array}{l}\text { Tenencia de la } \\
\text { tierra (1) }\end{array}$ & $\begin{array}{c}\text { Ejido con una } \\
\text { extensión de } 848 \text { ha } \\
\text { Tamaño promedio } \\
\text { de las parcelas: } 1.16 \\
\text { ha }\end{array}$ & $\begin{array}{l}\text { Ejido con una } \\
\text { extensión de } 1466 \text { ha } \\
\text { Tamaño promedio de } \\
\text { las parcelas: } 3.02 \text { ha }\end{array}$ & $\begin{array}{c}\text { Dos ejidos, uno con } \\
1103 \text { ha; otro con } \\
192 \text { ha. } \\
\text { Tamaño promedio } \\
\text { de las parcelas: } \\
0.55 \text { ha }\end{array}$ & $\begin{array}{l}\text { Ejido con una } \\
\text { extensión de } 1473 \text { ha } \\
\text { Tamaño promedio de } \\
\text { las parcelas: } 5.47 \text { ha }\end{array}$ \\
\hline $\begin{array}{l}\text { Acceso a } \\
\text { mercados(2) }\end{array}$ & $\begin{array}{c}\text { Mercado a } 32 \\
\text { kilómetros. Hay } \\
\text { transporte colectivo }\end{array}$ & $\begin{array}{c}\text { Mercado a } 28 \\
\text { kilómetros. Hay } \\
\text { transporte colectivo }\end{array}$ & $\begin{array}{l}\text { Mercado a } 47 \\
\text { kilómetros }\end{array}$ & $\begin{array}{c}\text { Mercado a } 24 \\
\text { kilómetros. Hay } \\
\text { transporte colectivo. }\end{array}$ \\
\hline Cultivos (2) & $\begin{array}{c}\text { Café; verduras y } \\
\text { chayote }\end{array}$ & $\begin{array}{c}\text { Café y maíz; calabaza, } \\
\text { chayote y yuca }\end{array}$ & $\begin{array}{c}\text { Pastos, sandía y } \\
\text { pepino }\end{array}$ & $\begin{array}{c}\text { Maíz y frijol; calabaza } \\
\text { y yuca }\end{array}$ \\
\hline $\begin{array}{l}\text { Otras actividades } \\
\text { económicas (2) }\end{array}$ & $\begin{array}{c}\text { Comercio } \\
\text { (pequeñas tiendas } \\
\text { de abarrotes), } \\
\text { albañilería y } \\
\text { carpintería }\end{array}$ & $\begin{array}{l}\text { Albañilería y } \\
\text { carpintería }\end{array}$ & $\begin{array}{c}\text { Pesca, turismo, } \\
\text { ganadería, ordeña y } \\
\text { albañilería }\end{array}$ & $\begin{array}{l}\text { Comercio (pequeñas } \\
\text { tiendas de abarrotes) }\end{array}$ \\
\hline $\begin{array}{l}\text { Nivel de ingreso, } \\
\text { estadísticas } \\
\text { municipales (3) }\end{array}$ & $\begin{array}{c}70.4 \% \text { pobreza; } \\
\text { 23.7\% extrema } \\
\text { pobreza. } \\
\text { En } 2005: \\
\text { IDH } 0.7167 \\
\text { salud } 0.7989 \\
\text { educación } 0.7348 \\
\text { ingreso } 0.6165\end{array}$ & $\begin{array}{c}\text { 92.8\% pobreza; } \\
59.5 \% \text { extrema } \\
\text { pobreza. } \\
\text { En 2005; } \\
\text { IDH } 0.5673 \\
\text { salud } 0.6768 \\
\text { educación } 0.5961 \\
\text { ingreso } 0.4292\end{array}$ & $\begin{array}{c}76.7 \% \text { pobreza; } \\
\text { 26.1\% extrema } \\
\text { pobreza. } \\
\text { En 2005: } \\
\text { IDH 0.7300, } \\
\text { salud 0.7966, } \\
\text { educación } 0.7718 \text {, } \\
\text { ingreso } 0.6214\end{array}$ & $\begin{array}{c}\text { 85.2\% pobreza; } \\
\text { 40.4\% extrema } \\
\text { pobreza. } \\
\text { En 2005: } \\
\text { IDH } 0.6767 \\
\text { salud } 0.7458 \\
\text { educación } 0.6742 \\
\text { ingreso } 0.6100\end{array}$ \\
\hline $\begin{array}{l}\text { Historia de la } \\
\text { migración (2) }\end{array}$ & Inició en 1970 & Inició en 1990 & Inició en 1990 & Inició en 1990 \\
\hline $\begin{array}{l}\text { Tamaño del } \\
\text { poblado (4) }\end{array}$ & $\begin{array}{c}\text { 1,274 habitantes; } \\
287 \text { viviendas } \\
\text { particulares } \\
\text { habitadas }\end{array}$ & $\begin{array}{c}\text { 1,147 habitantes; } 245 \\
\text { viviendas particulares } \\
\text { habitadas }\end{array}$ & $\begin{array}{c}\text { 1,778 habitantes; } \\
440 \text { viviendas } \\
\text { particulares } \\
\text { habitadas }\end{array}$ & $\begin{array}{c}158 \text { habitantes; } \\
38 \text { viviendas } \\
\text { particulares } \\
\text { habitadas }\end{array}$ \\
\hline
\end{tabular}

Fuente: (1) "Padrón e historial de núcleos agrarios. Registro agrario nacional”. Disponible en phina.ran.gob.mx [consultado en agosto de 2012]. (2) Información general de las comunidades donde se realizaron las encuestas: La Competencia, Huitiupán; El Águila, Cacahoatán; Veinticuatro de Febrero, Villa Corzo y Manuel Ávila Camacho “Ponte Duro", Tonalá, Chiapas. (3) Disponible en http://www.undp.org.mx/desarrollohumano/disco/index.html [consultado en julio de 2012]. (4) "Catálogo de localidades", SEDESOL. Disponible en http://www.microrregiones.gob.mx/catloc/ [consultado en julio de 2012]. 